\title{
Factors affecting the performance of South African municipal officials: stakeholders' perspectives
}

\section{Commonwealth Journal of Local Governance}

Issue 25: December 2021

http://epress.lib.uts.edu.au/ojs/index.php/cjlg

\section{Tyanai Masiya}

School of Public Management and Administration

Faculty of Economic and Management Sciences

University of Pretoria

Pretoria

South Africa

Email: tyanai.masiya@up.ac.za

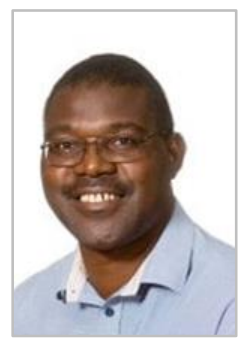

\section{Yul Derek Davids}

Developmental Capable and Ethical State

Human Sciences Research Council

116-118 Buitengracht Street

Cape Town, 8000

South Africa

Email: ydavids@hsrc.ac.za

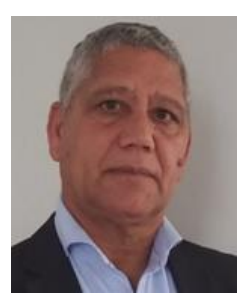

\section{Mary S Mangai}

School of Public Management and Administration

Faculty of Economic and Management Sciences

University of Pretoria

Pretoria

South Africa

Email: mary.mangai@up.ac.za

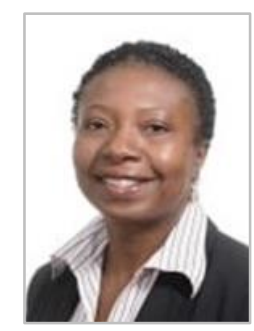

\begin{abstract}
Since the inception of the democratically elected post-apartheid government, South Africa has experienced growing numbers of protests about inadequate provision of basic municipal services. Recent studies have revealed that the poor performance of municipal officials contributes towards poor municipal service delivery. This article is based on a study which used qualitative key stakeholder interviews to analyse the performance of South African municipal officials, specifically in the delivery of services. It found that the following inter-related factors were responsible for the lack of performance: an unsupportive institutional environment, negative power struggles, over-regulation, political interference, a tense and bureaucratic environment, lack of coherent management systems, absence of a culture of excellence, poor skill utilisation, poor oversight mechanisms, weak capacity to engage in collaborations, and lack of trust between councillors from different political parties. The study concludes that for South African municipalities to meet their constitutional obligations to deliver
\end{abstract}

DOI: https://doi.org/10.5130/cjlg.vi25.7701

Article History: Received 23/04/21; Accepted 30/10/21; Published 30/12/21

Citation: Commonwealth Journal of Local Governance 2021, 25: 97-115, https://doi.org/10.5130/cjlg.vi25.7701

(C) 2021 Tyanai Masiya, Yul Derek Davids and Mary S Mangai. This is an Open Access article distributed under the terms of the Creative Commons Attribution 4.0 Unported (CC BY 4.0) License (https://creativecommons.org/licenses/by/4.0/), allowing third parties to copy and redistribute the material in any medium or format and to remix, transform, and build upon the material for any purpose, even commercially, provided the original work is properly cited and states its license. 
optimal basic services to the people, the government must, inter alia, invest in building the capacity of municipal officials through the development of skills and other crucial local government interventions and transformations. The municipalities should also depoliticise local government and promote nonpartisan appointment of municipal officials.

Keywords: Capacity, municipal officials, service delivery, South Africa, stakeholders, systems theory

\section{Introduction}

Municipalities in South Africa are mandated to deliver services that meet basic communal needs such as housing, water and sanitation, land, electricity and infrastructure (Dassah 2012; Reddy 2016). The municipality as an institution is considered an engine for local development and central to service delivery (Maphumulo and Bhengu 2019; Masiya et al. 2019). South Africa has also adopted the concept of 'developmental local government' and, in conferring this developmental role on municipalities, the government has implemented an elaborate statutory framework and obligations to operationalise it. Developmental local government means that a local government should be committed to work with citizens and groups within the community to find sustainable ways to meet their social, economic and material needs and improve the quality of their lives.

First, South Africa constitutionalised local government. Section 152 of the 1996 Constitution mandates municipalities to provide local communities with sustainable services. In promoting a developmental approach, Section 153 (1) requires municipalities to structure and manage their respective administrations, and to budget and plan, so as to prioritise the provision of basic services to communities. Furthermore, municipalities must also promote the social and economic development of the communities they service. The Bill of Rights provides those communities with the fundamental right of access to social services.

Second, in 1998 the government promulgated a White Paper that sought to operationalise 'developmental local government' institutions by compelling them to work with the citizenry and groups within the community to find sustainable ways to meet their social, economic and material needs as well as enhance their quality of life. Key developmental outcomes identified in the White Paper include that municipalities should focus on the provision of sustainable household infrastructure and services and create liveable and integrated local areas.

Third, the municipal developmental mandate is further expressed in the Local Government: Municipal Systems Act 2000. Among other provisions, the Act assigns municipalities the responsibility to promote access to affordable services and to encourage local community participation in municipal affairs. Furthermore, the Act outlines principles, mechanisms and processes which enable local governments to achieve their developmental mandate. 
Fourth, in seeking to foster sustainable service delivery through community participation, the Local Government: Municipal Structures Act 1988 stipulates the ward system. It mandates the creation of ward committees which are required to facilitate community participation and enhance communication between the municipal council and local communities, as well as enable the identification of community needs and fine-tune municipal programmes and projects to accommodate local circumstances and interests. In other words, the Act establishes a vehicle through which local communities express their views, needs and preferences to the municipalities.

Fifth, the White Paper on Transforming Public Service Delivery (1997) acknowledges a legitimate expectation on the part of citizens to receive services from municipalities, and orients the latter to optimise access to services. Municipalities are encouraged to consult citizens about the level and quality of services and, where possible, give them a choice of the services offered. Next, municipalities are required to inform the citizenry of the level and quality of services they will receive so that they are aware of what to expect. Furthermore, the citizens must be provided with detailed and accurate information about the services to which they are entitled. Finally, municipalities must be open and transparent: they are expected to inform citizens of how service departments are managed and the costs involved, as well as give details of persons who are in charge.

Sixth, the Municipal Regulations on Minimum Competency Levels were introduced by the country's National Treasury in 2007. These aimed to, inter alia, professionalise the local government sector, make it a career choice for talented officials, and to some extent mitigate certain root causes of poor financial management and service delivery (National Treasury 2015).

It is argued that South Africa has some of the most advanced statutory frameworks and obligations meant to promote service delivery in Africa (Skenjana and Afesis-corplan 2011). Despite such provisions, extant literature reveals that service delivery has been deteriorating and has occasionally become unreliable enough to endanger communities (Mamokhere 2019; Ntsikelelo et al. 2020; Kemp and Vyas-Doorgapersad 2020). According to Reddy (2016, p. 4), "a large percentage of local communities are yet to receive rudimentary services and for most township residents the most basic of service delivery, getting a pavement fixed or the rubbish cleared that is piled up on the streets, is a distant dream".

The result has been persistent and occasionally violent service delivery protests (Morudu and Halsall 2017; Alexander et al. 2018; Naidoo and Ramphal 2018). Morudu and Halsall (2017) claim that protests are linked to inadequate provision of basic services at municipal level, and more protests occur in areas where there are severe shortages of one or more basic services, namely water, electricity, sewerage, sanitation and refuse collection. Furthermore, research presents the overall transition from apartheid to democracy as having been shallow. Concrete transition benefits failed to reach the majority of those previously disadvantaged, a situation which brought about a resurgence of resistance from the poor 
through service delivery protests (Siwisa 2008; Alexander 2010). Booysen (2007) additionally contends that protests emanate from the fact that, in many instances, municipalities are dysfunctional.

This proliferation of service delivery protests, which have become increasingly violent and are reported regularly in the media, requires an exploration of the underlying causes of deteriorating service delivery. The minister of finance asserted in the 2020-21 budget statement that "For all South Africans, the 'state' is their municipality" (Mboweni 2020). Consequently, it is acknowledged that municipalities provide basic services and are a powerful redistribution tool.

The Auditor-General of South Africa (AGSA) report (2018) of the period 2017-2018 argued that one of the key causes of poor service delivery was lack of effective performance by municipal officials. AGSA argued that adverse municipal audit outcomes was an indication that municipal officials' actions were directly linked to the perennial problem of non-compliance with municipal regulations. This led, amongst other problems, to irregular expenditure of R62.6bn (US\$3 814102756 ) during the 2017-18 financial year. The ensuing Public Audit Amendment Act 2018 is designed to address challenges of accountability and service delivery, with a specific focus on enhancing the actions of municipal officials.

It is in this context that this article seeks to analyse, and generate an understanding of, factors affecting the performance of municipal officials more than 25 years after the introduction of a democratic local government system. In doing this, it is important to note that organisational structures and systems can also impact municipal officials' capacity because they have a bearing on creative thinking and sound performance. Nevertheless, research reveals that lack of effective service delivery at municipal level can be largely attributed to the performance of municipal officials (Asha and Makalela 2020; Mutyambizi et al. 2020; Sibanda et al. 2020).

The remainder of this article is structured as follows. The following section outlines the research methodology that was adopted to gather and analyse data. Then the study provides background information on the capacity constraints associated with municipal service delivery, followed by a discussion of systems theory to better understand service delivery and the multiple actors in the process. The results of the study are then presented and discussed, followed by a set of recommendations and a conclusion.

\section{Methodology}

The study reported in this article is part of a broader research project which adopted a mixed-methods approach comprising an extensive review of literature, in-depth one-on-one interviews with key municipal stakeholders, focus group discussions, and a quantitative online survey of public officials at eight targeted municipalities. Two municipalities were selected from each of four provinces in South Africa. The fieldwork was implemented in stages. Each municipality was targeted individually. The in- 
depth interviews were conducted via telephone calls and online platforms such as Zoom and Microsoft Teams.

For this article the in-depth interviews are utilised to provide more nuanced and detailed information to inform skills development and capacity interventions, but not to generalise to a larger population (Charmaz 1990). However, as part of the broader research project they are utilised to triangulate the findings with those of the online survey and the focus groups.

The research instrument sought participants' views on the following key thematic areas: 1) Challenges public officials face working at municipalities; 2) The general functioning and performance of the municipality; 3) Contextual factors which impact on the performance of the municipality; 4) Impacts of other government departments or external organisations on the performance of the municipality; 5) Organisational culture of the municipality; 6) Personal needs and values to perform your job; 7) Resources needed to perform your job; 8) Leadership practices and challenges; 9) Clarity of the roles and responsibilities of municipal officials; 10) Qualifications of officials to perform their job; 11) Skills development strategies; 12) Alignment of policies and procedures to the strategic plan; 13) Community engagement and collaboration with stakeholders; and 14) Suggestions to enhance the officials' capacity and skills.

The in-depth interview schedule was based on a detailed literature review on local government, which included: Chapter 13 of the National Development Plan (NDP) titled 'Building a capable and developmental state' (The Presidency, Republic of South Africa 2011); the 1998 White Paper on local government (Republic of South Africa 1998); the Local Government Turnaround Strategy of 2009 (Republic of South Africa 2009); and the National Implementation Framework towards the Professionalisation of the Public Service (National School of Government 2020). A panel of two research experts and two practitioners reviewed the research instrument content to establish its conformance with the overall project objectives and whether it adequately covered the skills and capacity areas of investigation as well as internal and external factors which impact on the overall performance of public officials at municipal level.

A total of 14 one-on-one interviews were conducted with key stakeholders in the public, private and civil society sectors. The list of key informants included academics, staff from key stakeholder organisations in local government - for example, the South Africa Local Government Association (SALGA), the Department of Cooperative Governance and Traditional Affairs, and municipal managers - and representatives from civil society organisations (CSOs). Interviewees were selected irrespective of their provincial location to acquire a broad and in-depth overview of issues related to skills and capacity from a national perspective. COVID-19 health and safety protocols required mostly online and telephone interviews, but a few interviews were conducted face-to-face before the nationwide lockdown was implemented in late March 2020. 
Most of the interviews lasted between 60 and 90 minutes. Three researchers conducted the in-depth interviews and each was responsible for recording and taking detailed field notes during the interview. Once the interviews were completed, they were tasked with transcribing the recording verbatim. The transcripts were then coded according to the questionnaire themes. Each researcher involved in the coding process was instructed to assign an equal weight to each statement and thematic area.

The study employed a grounded theory approach. It did not employ a software package to assist with data analysis because it was feasible for the researchers themselves to categorise the data into themes. This approach conformed with Deterding and Waters (2021), who reason that the grounded theory approach was developed based on projects with a small number of interviews, and which are therefore capable of analysis by the researchers themselves.

\section{Literature review}

\section{Capacity in municipal service delivery}

Municipalities are the sphere of government closest to the citizens. They are central to providing effective basic services to local communities. At municipal level, Chen et al. (2014) define service delivery to be the meeting of basic needs which local communities are dependent upon, for example water, electricity, sanitation, infrastructure, healthcare and housing. Ndevu and Muller (2018, p. 182) posit that municipalities are at the front line of public service delivery and are the first point of contact between an individual and a government institution. Effective and efficient service delivery depends on municipal capacity.

Whittle et al. (2012) noted that the literature on organisational capacity offers a variety of ways in which capacity can be understood. It is therefore difficult to reach a standard understanding and description of what constitutes 'capacity' and 'capacity-building', and which factors influence organisational capacity and effectiveness (Sobeck and Agius 2007). However, Milen (2001) provides a working definition of what constitutes capacity. They assert that it is the ability of people, organisations and systems to achieve set objectives. Therefore, in the context of municipalities, capacity relates to the ability to provide effective services to local communities. It refers to the ability of the municipality to achieve specific outcomes through set internal functionalities and processes - what people do, and the systems and structures that exist within the municipal organisation.

Whittle et al. (2012) posit that this 'whole-of-organisation' perspective relies on five fundamental 'capacities', namely: (a) competent (qualified and experienced) people; (b) programmes being relevant to community needs; (c) efficient organisational structures; (d) adequate resources; and (e) an effective way of working. This article analyses the extent to which South African municipal officials are affected by capacity constraints in those areas, and how these constraints may impact their ability to address current service delivery challenges. 
In general, municipal service delivery in South Africa still reflects the legacy of apartheid government policies, which were founded on a racial separatist ideology without due regard to equitable service delivery. Essentially, the infrastructure backbone of the country was not built to be inclusive. Improving service delivery has, therefore, remained a complex and difficult task. Consequently, too many communities throughout the country still live in abject poverty with inadequate infrastructure. According to Masuku and Jili (2019), inadequate municipal capacity has contributed towards the lack of basic services such as housing, water and sanitation. However, the Public Servants Association (2015) argues that the popular sentiment is rather that there is institutional dysfunctionality across municipal government.

According to Reddy (2016, p. 5):

There is constant reference by municipal functionaries to 'world-class cities', but at the same time the traffic lights are quite often not functioning; the grass on the verges is not regularly trimmed; water pipes are constantly broken or even leaking; potholes are multiplying; telephones are often unanswered and there is widespread urban decay throughout the municipal areas, resulting in a depreciation of property values and loss of potential income for the municipalities.

Thus, despite commendable goals having been set by government to enhance the quality of service delivery at municipal level, existing research, media reports and community protests reveal that municipal services fail to meet basic standards and the reasonable expectations of the citizenry. There is an urgent need to bring together theoretical insights and empirical data to enable a better understanding of the factors which influence the performance of municipal officials as well as to explore the potential to improve municipal service delivery in South Africa.

\section{Systems theory}

The present study applies systems theory to understand the influence of the performance of municipal officials on service delivery. Systems theory has gained currency with academics and policy-makers alike in recent years (Mansoor and Williams 2018). It generates a better understanding of policy implementation and bureaucratic performance, as well as its complexity and unpredictability (Hawe 2015).

Systems theory can be credited to David Easton, a reputable scholar of political science who analysed politics from the perspective of systems in his famous work The Political System (1953). The political system comprises those identifiable and inter-related institutions and activities (which we generally think of as government institutions and political processes) in a society that generate authoritative decisions (Anderson 2015). Municipalities can be considered a political system's response to demands for service delivery at local level.

In seeking to examine factors which affect South African municipal officials' performance and to provide recommendations on how it can be improved, this study draws from systems theory to consider 
the multiplicity of actors who potentially impact that performance. Stewart and Aryes (2001, p. 84) postulate that:

the systems approaches suggest that determining what is causing a problem may be to ask the wrong question. The 'problem' is itself a manifestation of a set of inter-related elements, at least some of which reflect the effects of past policy choices. In other words, there is a problem situation, rather than an identifiable causal factor.

In explaining the systems approach, the Organisation for Economic Cooperation and Development (OECD) (2017) asserts that action, processes and outcomes are based on relationships; that is, the connections between individual pieces, rather than the pieces themselves. Thus, in terms of this theory, the individual pieces in municipal service delivery (for example municipal officials, stakeholders, citizens, elected officials, other spheres of government etc) are important, but the way they work together makes the difference as to whether the municipalities as systems succeed. Systems can also exist within each other, such as a department within a municipality or a unit within a municipal department. Given this complexity, the relationships between causes and effects are neither linear nor simplistic.

To comprehend how a system of public service delivery should be conceptualised, Mansoor and Williams (2018, p. 8) argue that we must apprehend how the system works in terms of " $a$ ) the functions it performs; $b$ ) its main stakeholders; c) inter-relationships or flows of information, accountability, or resources among sub-systems; and d) the levels at which various stakeholders operate". Accordingly, the key to a successful municipal service delivery system is the process which defines not only the relationships between elements but also the way in which the customer or service flows through the system. Well-designed processes based on desired outcomes and purposes create efficient, flexible and integrated systems.

Applying the systems approach to municipal problems which are ordinarily complex is useful in mapping the dynamics which underpin municipalities, how the relationship between system components affects how they function, and the nature of interventions which can lead to enhanced outcomes. The system lens assists observers to comprehend how systems are structured and operate. This implies understanding what lies between the parts: their relationships, and the gaps between. Furthermore, it enables reflection on possible action which can be taken based on this understanding (ie design and design thinking) and formulation of options that can be tested before being applied within the systems in question.

Therefore, utilisation of the systems approach to analyse service delivery can help municipalities to confront in a holistic manner problems which cut across administrative and territorial boundaries. In developing solutions to any municipal capacity challenges, including those of municipal officials, the process should be to develop "a vision for a desired future outcome, define the principles according to 
which that future system will operate, and start to implement a set of interventions that will transform the existing system into the future system" (OECD 2017, p. 9).

In municipal service delivery, application of the systems approach is also appealing because changing the entire municipal system simultaneously is an untenable intervention, as services must be provided continuously: they cannot be stopped, redesigned and restarted. In that regard, a systems approach enables the roll-out of new practices in targeted areas while core processes continue to function.

\section{Study results}

The research findings reported here have been structured around eight interconnected themes which emerged from the interviews as factors which affect effective municipal officials' performance. These themes are presented in detail in the sub-sections that follow and reviewed in the Discussion section.

\section{Unsupportive institutional environment}

The interviews established that public officials at various levels, regardless of their skills, are confronted by an unsupportive institutional environment coupled with a bureaucratic and rigid institutional structure which inhibits the adequate absorption and application of new skills, policies, regulations and practices. This finding is consistent with recent research by Moodley (2018) whose study revealed that an unsupportive institutional environment was among the top three issues which posed critical challenges to municipal service delivery. Institutional environments are influential through incentives which they create that have a strong bearing on the degree to which officials' performance can be enhanced and sustained.

\section{Negative power struggles and political interference}

Overall, the interviews revealed that the picture of the internal municipal environment is primarily one of negative power struggles between the political and the administrative spheres. Respondents reported a challenging organisational culture which adversely affects the morale and agency of officials. ${ }^{1}$

Respondents also reported that in terms of the political-administrative interface, political interference is visible in "the politics of the day, the encroachment of politicians on officials' sphere of responsibility and also officials who are affiliated to a political party". They hold that interference and institutional context has led to the development of a "commanding authoritarian language from politicians" which is very unappreciative of officials' skills and expertise and causes officials to feel pessimistic about their ability to undertake their tasks in a professional manner, and thereby creates dissonant workplaces. One of the respondents commented that "there is limited space for politicians and officials to engage with each other on key issues in a constructive manner". The respondents argued that officials often

\footnotetext{
${ }^{1}$ Due to the small sample size, it was not possible to indicate the source of quotes and also maintain necessary confidentiality.
} 
feel unprotected from this tension and political priorities frequently override formally approved implementation plans and administrative needs. In their analysis, the common feature is a power-play relationship: that is, the politicians' decisions override those of the officials. The common notion is that a 'dissonant' workplace environment "creates a climate of instability and fear; people are always alert for being attacked. Their brains are [in] defence mode and they can't think creatively". Moreover, hardworking officials at municipal manager level are swamped by politics and feel that they cannot do much to counteract these pressures. An interviewee argued: "Officials fear politicians when trying to solve problems. They do their best but know that as soon as there is a small error they can be thrown out, so it's better to rather not do much. That is the culture."

Furthermore, an experienced consultant and former civil servant observed that: "The major challenge I see in most senior officials, especially managers, is political interference; also, within people themselves, their own political involvement and sensitivities... there is a tension between the right thing to do as a public official, versus the right thing to do given political and social expectations."

\section{Lack of trust due to political appointments}

An interview participant also identified a 'deep' or entrenched organisation-wide lack of trust - between councillors from various political parties, between officials and oversight committees, and by councils distrusting senior officials' intentions. The participant attributed this to the prevailing political deployment arrangement under which councillors do not necessarily take the decision to appoint the municipal manager and approve the appointment of other senior officials, but instead regional political party structures make these strategic decisions. The result is that the municipal council is not always convinced of the skills and intentions of the municipal manager, whose conduct, decisions and advice are then subject to suspicion and challenge. The same suspicion applies to subsequent appointments by the municipal manager. Several interviewees reported that it is "common to have a high turnover or rotation of team and thematic leaders, as well as long-term acting appointments. This combination creates a climate of uncertainty and distrust where officials can't make meaningful decisions and undertake appropriate long-term planning that enables predictable service delivery."

\section{Over-regulated and tense bureaucratic environment}

For some of the respondents, municipalities are an over-regulated environment which places pressure on officials to fulfil multiple requirements to work with provincial and national departments. They hold that numerous regulations and a compliance-driven approach create a difficult working environment with complicated internal procedures. Attracting and retaining skilled persons and making the most of the skills officials possess or have acquired is difficult in this context.

During the interviews, the organisational environment in municipalities was described as tense and bureaucratic, characterised by a culture of commanding, under a compliance-driven mentality. One 
respondent commented that "the bureaucratic environment in South African municipalities is destroying many departments and innovation" because it inhibits people from collaborating across boundaries and being creative. The bureaucratic and rigid institutional set-up also appears to inhibit the absorption and application of new policies, regulations and practices. A manager from a nongovernmental organisation (NGO) and urban justice activist explained that:

We have seen that when policies and procedures are updated and improved, it takes a long time for officials to change their thinking and update their skills to steer implementation in the new directions. For instance, with the new housing policies we asked ourselves, do officials take time to think how to implement it and what skills are required? This is important not only for senior-level officials but for planners and those officials working on the ground... The upgrading [of] informal settlements policy allows for innovation and flexibility, but municipalities still go back to the Reconstruction and Development Programme (RDP) narrative and set-up of 'relocation' houses. While the policy speaks about the importance of public spaces, you don't see municipalities thinking of this. The system seems to prevent creativity on how human settlements should be [designed and developed].

\section{Absence of a culture of excellence}

The interviews indicated that there is no culture of excellence to support high-quality service delivery, oversight, coordination or coherent planning between the departments. Instead, "chaos, disarray, mistrust, poor oversight [and] lack of accountability" characterise organisational culture. A respondent noted that it is difficult to imagine any official or councillor feeling motivated to achieve excellence "when the entire local government sector is viewed as a failure... it would take a dedicated and strongwilled official to thrive in that environment." This argument suggests that there is no value attributed to excellence and striving towards it; rather, there is a culture of mediocrity and a general attitude of not taking jobs seriously or performing them with a sense of duty.

A senior representative of a well-established NGO which works closely with communities and local authorities agreed that the "organisational culture in most municipalities is negative and officials don't feel valued". This environment favours the many officials who want only job security, rather than the few who are committed to public service. The representative spoke of one senior manager who, while working in middle and senior management for a decade in a metropolitan council, has never had his performance assessed, or even participated in a team-building exercise - "they are on their own".

\section{Failure to upgrade skills}

The interviews pointed to a large mismatch between skills development plans, training efforts and the actual capacity of municipal officials to implement the acquired skills. The data (interviewed respondents) reveals that even when officials get exposed to new skills, the system does not encourage officials to apply them. A senior public official explained: "The difficulty comes with a municipal system that is not responsive to those skills. Furthermore, there are instances where well-qualified people join the municipality, but there is no system capacity to absorb and use those skills and eventually there is no institutional receptiveness to apply new knowledge, which is a contradiction." 
An interviewed NGO participant who conducted a municipal public accounts committee (MPAC) training workshop also noted that junior staff are neglected. They received no training or support from their seniors or from municipal officials to enable them to perform their tasks effectively.

\section{Poor oversight mechanisms}

Respondents argued that the severe dysfunctionality in some municipalities is exacerbated by poor oversight by national or provincial departments which have responsibility for local government. This is the case even though municipalities are mandated by law to report monthly and quarterly to the National Treasury, and quarterly to the Department of Cooperative Governance and Traditional Affairs. For example, a senior NGO official stated that: "You would assume that, before the Auditor-General comes at the end of the financial year, the departments that have oversight functions over $L G$ and that receive by law [quarterly] reports on $L G$ performance would pick up challenges... long before the AuditorGeneral." Such oversight responsibilities are stipulated in legislation such as the Local Government: Municipal Structures Act 1998 and the Municipal Finance Management Act 2003. In the context of these legislative provisions, municipal public accounts committees are expected to perform an internal oversight role, while external oversight is the responsibility of municipal audit committees. Yet it would appear these roles are rarely undertaken.

Respondents also noted that municipal oversight in principle also requires officials to ensure that communities have access to information, and that the provision of information should go beyond placing certain information online. Municipalities should, therefore, create conditions for the poor to access information, and consult communities to share insight from their lived experiences. In other words, municipalities must not just perceive IT and social media as the new 'sexy thing' to engage constituencies and stakeholders, because doing so can limit 'real' engagement and accountability. What is needed is meaningful engagement with communities and stakeholders to ensure that municipalities address their constituents' concerns and service delivery issues.

\section{Weak capacity to engage in collaborations}

The interviews further revealed that in the political sphere, and at senior management level, officials have relatively weak capacity to engage in collaborations, partnership-building and coalition politics, or to work with the private sector, community groups etc. An NGO manager felt that there was a need to train politicians to better understand and manage the administrative-political interface, because of its impact on public officials' capacity to operate, deliver and assemble key collaborations. The same participant emphasised that "municipalities and especially metros can't perform without good intergovernmental relations and partnerships with other institutions, not only provincial and national but local. The lack of effective relationships with parastatals for instance has caused delays of decades in major infrastructural projects." 
Internal collaboration is another challenge, with limited cooperation in evidence between officials. A participant said that "collaboration is actually punished by the system, with stories of departments punished for transferring resources to other departments". Overall, the interviews revealed that officials work in silos, and often employ competitive and non-collaborative approaches in their daily routine. Although officials hold coordination meetings, there is limited cooperation in terms of information and resource-sharing. A key informant deplored this, and offered a vision of more effective working : "it's about working smarter, collaborating and sharing resources both within and across nearby municipalities, and technology can assist communication within the institution, for instance by having a central repository of information that all departments are able to access and share." Beyond technological fixes, this is an important governance challenge which identifies a gap in planning and management skills.

Another interviewee also argued that services such as housing and waste require all departments and even neighbouring municipalities to work together. The participant commented that: "Collaboration requires blending your mandates, resources, plans, but this is actually discouraged and even punished by a compliance-driven system where officials are expected to primarily stick to tick (or fill) indicators."

\section{Discussion}

The application of systems theory has cast light on the complexity of the factors which affect South African municipal officials' performance, due to the multiplicity of actors. Interpreting the interview findings through this lens reaffirmed Hawe's (2015) postulation that systems theory generates an understanding of policy implementation and bureaucratic performance, as well as their complexity and unpredictability. The study results suggest that municipal officials often work in an unsupportive institutional environment characterised by onerous institutional and bureaucratic rules and regulations which impact negatively on their performance and job satisfaction. There is thus a need for greater and more focused support. Building municipal officials' capacities is essential if municipalities want to fulfil and achieve the obligations stipulated for them in Chapter 10, section 195(1) of the 1996 Constitution and other national policy documents. In the South African municipal context, local government skills development is critical because it will lay the foundation for a more people-oriented local government system, and will determine local government's ability to meet the demands of the people for democracy, reconstruction and development.

For local government to work better, there is a need to invest more in capacity-building for both councillors and officials. The National Development Plan (NDP) in its Chapter 13 underscores the need to make public service and local government careers of choice. Furthermore, South Africa should focus on building public officials' skills and capacity at all levels. Top-level recruitment and management should be based on experience and expertise, rather than political affiliation, while at the junior level 
the state should focus on developing the skills and expertise required for future public service cohorts (National Planning Commission 2011).

According to the Public Service Commission Act 2006, people who form part of an interview committee for a senior public service post must include all represented political parties within that municipality. The interview committee must interview the candidates, verify their qualifications, and work together with the legal and monitoring team. The personnel management or human resources department must also be independent of any political affiliation to enable it to hire candidates based on competency and not political affiliation. This will be challenging, but it is important if municipalities want to deliver on their mandate and adhere to the Batho Pele principles of putting people first.

Municipal officials also seem to lack the ability to pursue effective collaboration with communities, NGOs and businesses. Again, capacity-building is required. For example, multi-sectoral approaches are needed to service communities in terms of housing and waste disposal. The launch of the District Development Model on 26 November 2019 in the Waterberg District of Limpopo Province is a step in the right direction. Under this model all three spheres of government must coordinate and integrate development plans and budgets, and mobilise government and civil society capacity and resources as well as business, labour and communities to achieve growth and job creation (Department of Cooperative Governance 2020). According to Kariuki (2020), an integrated district model is important for sustainable and developmental local government, but it must be fully supported by an involved citizenry (including social partners) or the model will not work as intended. It remains to be seen how successful this new model will be in future.

Municipal officials' internal work environment is further impeded by power struggles between the municipal administrative and political leadership. Easton's (1953) political systems theory is illuminating in this context. According to his perspective, community interest should be prioritised and political party activities and agendas should not overshadow service delivery issues. Politicians should not intimidate municipal officials to make decisions which would favour them rather than the communities they serve. Likewise, it is essential that municipal officials consider the interests of the people ahead of those of a political party. Failure to do so will negatively impact municipal performance. The power struggles, political interference and political appointments of party agents are contributory factors which limit trust between officials. Distrust then creates an environment of suspicion which casts doubt on the credibility of decisions taken by municipal officials who are loyal to the party.

There is an urgent need to rethink and establish innovative ways to inhibit administrative malpractice within municipalities. Local government transformation in South Africa has placed considerable pressure on municipalities to manage their administrative and financial resources effectively, economically and efficiently to meet their developmental mandate. Therefore, municipalities need to 
implement sound administrative and financial management processes as envisaged in the statutory framework by appointing qualified and capable officials, including chief financial officers and internal auditors with appropriate skills. Importantly, municipal officials must account for outcomes, rather than just for budget expenditure. As additional resources are transferred to local government, there is also a need to strengthen institutions to enforce accountability for use of public resources (National Treasury 2018; Kumar and Fester 2019).

Research by Reddy (2016) confirms that political infighting and related clashes between the political and management wings of local government affect municipal service delivery adversely. Masiya et al. (2019) state that conflicts between managerial officials and elected officials in certain instances emerge because managerial officials are either unwilling or unable to share decision-making power with elected representatives, while politicians often encroach on officials' sphere of responsibility. In closely related observations, Tshishonga (2014) and Shava and Chamisa (2018) have argued that South Africa pursues a politicised bureaucratic model which is anchored in the cadre deployment strategy of the African National Congress (ANC). This involves the appointment of party loyalists to public institutions, purportedly to enhance public reporting lines and ensure that the institution stays true to the party's mandate as endorsed by voters. However, this policy and political influence in general weaken municipal officials' performance within South African municipalities. Decisions are heavily influenced by the dominant political party (Masuku and Jili 2019) and there is often a lack of political will to make sound appointments beyond party loyalty. According to Reddy (2016, p. 3), "the politicisation of local government has created a challenge in this regard as the necessary skills at the local level are, at best, marginally available, and the political and management will to take firm and decisive action is lacking". Hence allegations of appointments of unqualified personnel in municipalities, based on political patronage and nepotism, abound.

\section{Conclusion}

Overall, the key stakeholder interviews revealed that there is a lack of coherent management systems in South African local governments, which can make it impossible to make good decisions. There is often no political will to support innovation, and resistance thereto is common. Crucially, in terms of the quality of service delivery, the report of the Auditor General South Africa (2019) on audit outcomes for the period 2018-2019 noted that most municipalities and similar public institutions were not compliant with service delivery improvement efforts, such as the drafting of service charters, delivery improvement plans and human resources plans. Furthermore, the lack of financial controls in municipalities contributed to huge irregular expenditure.

Clearly, there are parts of the municipal system which do not function optimally and need strengthening. In line with systems theory, attention must be given to all actors in the system if one wants to enhance 
the provision of municipal services. It is against this background that the opinions of key stakeholders were sought.

The study found that the municipalities need to depoliticise local government and promote non-partisan appointment of municipal officials. Further, greater and more focused support is needed to enhance municipal officials' skills and capacity. Implementation of targeted skills development plans, training and capacity interventions are essential for more effective and efficient service delivery. Furthermore, strong oversight and monitoring is required to enhance performance and address corruption as well as political interference in municipal administration.

For the municipal system to deliver the required outcomes the interests of communities must be prioritised. Effective collaboration with civil society organisations, NGOs and businesses, as well as collaboration between municipalities and with provincial and national departments, is needed to underpin improved municipal service delivery. The study, therefore, underscores that all parts of the municipal system are inter-related and must be connected to provide a better quality of life for all communities.

\section{Declaration of conflicting interest}

The author declared no potential conflicts of interest with respect to the research, authorship, and/or publication of this article.

\section{Funding}

The authors received no financial support for the research, authorship, and/or publication of this article.

\section{References}

Asha, A. and Makalela, K. (2020) Challenges in the implementation of integrated development plan and service delivery in Lepelle-nkumphi Municipality, Limpopo Province. International Journal of Economics and Finance Studies, 12, 1-15. https://doi.org/10.34109/ijefs.202012101

Alexander, P. (2010) Rebellion of the poor: South Africa's service delivery protests - a preliminary analysis. Review of African Political Economy, 37, 25-40. https://doi.org/10.1080/03056241003637870

Alexander, P., Runciman, C., Ngwane, T., Moloto, B., Mokgele, K. and Van Staden, N. (2018) Frequency and turmoil: South Africa's community protests 2005-2017. South African Crime Quarterly, 63, $27-42$. https://doi.org/10.17159/2413-3108/2018/v0n63a3057

Anderson. J.E. (2015) Public policy making. $8^{\text {th }}$ ed. Stamford: Cengage Publishers.

Auditor-General South Africa. (2018) Consolidated general report on national and provincial audit outcomes (2017-18). Available at: https://www.agsa.co.za/Portals/0/Reports/PFMA/201718/GR/PFMA201718\%20Consolidated\%20General\%20Report.pdf [Accessed 20 December 2020].

Auditor-General South Africa. (2019) Consolidated general report on national and provincial audit outcomes. (2018-19). Available at: https://www.agsa.co.za/Portals/0/Reports/MFMA/201819/GR/MFMA\%20GR\%20201819\%20Final\%20View.pdf [Accessed 13 December 2020].

Booysen, S. (2007) With the ballot and the brick: the politics of attaining service delivery. Progress in Development Studies, 7 (1), 21-32. https://doi.org/10.1177/146499340600700103 
Charmaz, K. (1990) 'Discovering' chronic illness: using grounded theory. Social Science \& Medicine, 3 (11), 1161-1172. Available at: https://www.sciencedirect.com/science/article/abs/pii/027795369090256R [Accessed 13 September 2020].

Chen, L., Dean, J., Frant J and Kumar, R. (2014) What does "service delivery " really mean? Available at: https://www.cfr.org/blog/south-africa-what-does-service-delivery-really-mean [Accessed 10 April 2020].

Dassah, M.O. (2012) A critical analysis of factors underlying service delivery protests in South Africa. Journal of African and Asian Local Government Studies, 1(2), 1-28.

Department of Cooperative Governance. (2020) District development model. Available at: https://www.cogta.gov.za/ddm/

Deterding, N.M. and Waters, M.C. (2021) Flexible coding of in-dept interviews: a twenty-first-century approach. Sociological Methods \& Research, 5 (2), 708-739. https://doi.org/10.1177/0049124118799377

Easton, D. (1953) The political system: an inquiry into the state of political science. New York: Alfred A. Knopf.

Hawe, P. (2015) Lessons from complex interventions to improve health. Annual Review of Public Health, 36 , 307-323. https://doi.org/10.1146/annurev-publhealth-031912-114421

Kariuki, P. (2020) Local government revamp needed for district development model to work. Business Day, 29 September 2020. Available at: https://www.businesslive.co.za/bd/opinion/2020-09-29-localgovernment-revamp-needed-for-district-development-model-to-work/

Kemp, M.J. and Vyas-Doorgapersad, S. (2020) Service delivery challenges in Protea Glen, Johannesburg. Africa's Public Service Delivery and Performance Review, 8 (1), a368. https://doi.org/10.4102/apsdpr.v8i1.368

Kumar, A. and Fester, R. (2019) Fiscal futures: is there a space for better fiscal accountability in South Africa's metropolitan municipalities? International Budget Partnership. Available at: https://www.internationalbudget.org/2019/03/fiscal-futures-is-there-space-for-better-fiscalaccountability-in-south-africas-metropolitan-municipalities/ [Accessed 12 February 2020].

Mamokhere, J. (2019) An assessment of reasons behind service delivery protests: a case of Greater Tzaneen Municipality. Journal of Public Affairs, 20 (2). https://doi.org/10.1002/pa.2049

Masiya, T., Davids, Y.D. and Mazenda, A. (2019) Effective public participation in municipal service delivery: the case of Nyanga township. Administratio Publica, 27 (3), 27-47.

Maphumulo, W.T. and Bhengu, B.R. (2019) Challenges of quality improvement in the healthcare of South Africa post-apartheid: a critical review. Curationis, 42 (1), a1901. https://doi.org/10.4102/curationis.v42i1.1901

Mansoor, Z. and Williams, M.J. (2018) Systems approaches to public service delivery: lessons from health, education, and infrastructure. Paper prepared for the workshop Systems of Public Service Delivery in Developing Countries on 14-15 May 2018, at the Blavatnik School of Government, University of Oxford.

Masuku, M.M. and Jili, N.N. (2019). Public service delivery in South Africa: the political influence at local government level. Journal of Public Affairs, 19 (4). https://doi.org/10.1002/pa.1935

Mboweni, T. (2020). 2020 Budget Speech-Minister of Finance Tito Titus Mboweni. Available at: https://www.gov.za/BudgetSpeech2020 [Accessed: 12 January 2021].

Milen, A. (2001) What do we know about capacity building: an overview of existing knowledge and good practice. Geneva: Department of Health Service Provision, World Health Organization.

Morudu, H.D. and Halsall, J. (2017) Service delivery protests in South African municipalities: an exploration using principal component regression and 2013 data. Cogent Social Sciences, 3 (1). https://doi.org/10.1080/23311886.2017.1329106

Moodley, S. (2018) Why do planners think that planning has failed post-apartheid? The case of eThekwini Municipality, Durban, South Africa. Urban Forum, 30. https://doi.org/10.1007/s12132-018-9357-0

Mutyambizi, C., Mokhele, T., Ndinda, C. and Hongoro, C. (2020) Access to and satisfaction with basic services in informal settlements: results from a baseline assessment survey. International Journal of Environmental Research and Public Health, 17, 4400. https://doi.org/10.3390/ijerph17124400 
Naidoo, C. and Ramphal, R.R. (2018) The factors that affect public participation for effective municipal service delivery: a case of ward committees. South African Journal of Industrial Engineering, 29 (4), 82-93. https://doi.org/10.7166/29-4-1948

Ntsikelelo, B., Nomarwayi, T. and Bradshaw, G. (2020) Electoral violence and municipal demarcation in South Africa, 1994-2019: a violent service delivery protests perspective. Gender and Behavior, 18 (1), 1485714871.

National Planning Commission. (2011). National Development Plan 2030. Pretoria: Government Printers.

National School of Government. (2020) A national implementation framework towards the professionalisation of the public service. Government Gazette No. 44031. Available at: https:/www.thensg.gov.za/wpcontent/uploads/2021/01/Nat_Gov_Gazzette_24_December_2020.pdf [Accessed: 12 June 2020].

National Treasury. (2015) Minimum competency levels for municipal officials effective from October 2015. Available at: http://www.treasury.gov.za/comm_media/press/2015/2015093001\%20-\%20MinimumCompetencyState ment.pdf [Accessed 13 October 2020].

National Treasury. (2018) The state of local government finances and financial management as at 30 June 2018. Pretoria: Government Printers.

Ndevu, Z. and Muller, K. (2018) A conceptual framework for improving service delivery at local government in South Africa. African Journal of Public Affairs, 10 (4), 181-195.

Organisation for Economic Cooperation and Development. (OECD) (2017) Systems approaches to public sector challenges: working with change. Paris: OECD Publishing. https://doi.org/10.1787/9789264279865-en

Public Servants Association. (2015) The challenge of service delivery in South Africa: a Public Servants Association perspective. Available at: https:/www.psa.co.za/docs/default-source/psa-documents/psaopinion/psa_service_delivery.pdf?sfvrsn=8ce4a8_3 [Accessed 17 October 2020].

Reddy, P.S. (2016) The politics of service delivery in South Africa: the local government sphere in context. The Journal for Transdisciplinary Research in Southern Africa, 12 (1), a337. https://doi.org/10.4102/td.v12i1.337

Republic of South Africa. (1996) Constitution of the Republic of South Africa Act, of 1996. Pretoria: Government Printer.

Republic of South Africa. (1998) Local Government: Municipal Structures Act (Act 117 of 1998). Pretoria: Government Printer.

Republic of South Africa. (2000) Local Government: Municipal Systems Act (Act 32 of 2000). Pretoria: Government Printer.

Republic of South Africa. (1998) White Paper on local government. Pretoria: Government Printers.

Republic of South Africa. (2003) Municipal Financial Management Act (Act 56 of 2003). Pretoria: Government Printer.

Republic of South Africa. (2006) Public Service Commission Act 2006. Pretoria: Government Printer.

Republic of South Africa. (2009) Local government turnaround strategy 2009: working together, turning the tide in local government. Department Cooperative Governance \& Traditional Affairs. Available at: https://www.gov.za/sites/default/files/gcis_document/201409/locgovt-turnaround-strategy-25-november2009.pdf

Republic of South Africa. (2018) Public Audit Amendment Act (No. 5 of 2018). Pretoria: Government Printer.

Shava, E. and Chamisa, S. (2018) Cadre deployment policy and its effects on performance management in South African local government: a critical review. Politeia, 37 (1), 1-18. https://doi.org/10.25159/0256$8845 / 3849$

Sibanda, M.M., Zindi, B. and Maramura, T.C. (2020) Control and accountability in supply chain management: evidence from a South African metropolitan. Cogent Business \& Management, 7 (1). https://doi.org/10.1080/23311975.2020.1785105

Siwisa, B. (2008) Crowd renting or struggling from below? The concerned citizens' forum in Mpumalanga Township, Durban, 1999-2005. Journal of Southern African Studies, 34 (4), 919-936. https://doi.org/10.1080/03057070802456839 
Skenjana and Afesis-corplan, P.K.( 2011) Existing mechanisms for public participation at local government level. Available at https://ggln.org.za/media/k2/attachments/SoLG.2011-Afesis-corplan.pdf [Accessed: 23 February 2021].

Sobeck, J. and Agius, E. (2007) Organizational capacity building: addressing a research and practice gap. Evaluation and Program Planning, 30, 237-246. https://doi.org/10.1016/j.evalprogplan.2007.04.003

Stewart, J. and Ayres, R. (2001) Systems theory and policy practice: an exploration. Policy Sciences 34, 79-94. https://doi.org/10.1023/A:1010334804878

The Presidency, Republic of South Africa. (2011) National development plan: vision for 2030. Pretoria: National Planning Commission.

Tshishonga, N. (2014) Cadre development and its implications on service delivery in South Africa: a human development capability approach. Journal of Public Administration, 49 (3), 891-908.

Whittle, S., Colgan, A. and Rafferty, M. (2012) Capacity building: what the literature tells us. Dublin: The Centre for Effective Services. 